related to socio-economic changes in the country in the following years a doubling of the cases of tuberculosis up to 49.9/100 000 was observed in 1998. Recently there has been a tendency to arrest and slowly reduce incidence - up to 37.1/100 000 in 2007. One of the most affected groups at risk for the development and spread of tuberculosis in Bulgaria are the people from the Roma community. According to the National Statistical Institute (2001) 9\% of the population identified themselves as Roma. In Bulgaria there is no registration and analysis of health indicators by ethnic groups, therefore the assessment of the health of these communities is difficult. TB in Roma communities is higher than the national average prevalence. The goal of this study was to establish the prevalence and determinants characterising this distribution process. Preventive measures should be targeted at early development and improvement of living and working conditions to overcome social exclusion. Targeted epidemiological studies of morbidity among people in the Roma community, identification of risk factors and the development of preventive strategies are needed to combat tuberculosis.

\section{P2-439 MIGRANTS AND REFUGEES MENTAL HEALTH: A SYSTEMATIC REVIEW}

doi:10.1136/jech.2011.142976l.69

J Lindert, ${ }^{*} 0$ von Ehrenstein, E Brähler. Protestant University, Ludwigsburg, Germany

Introduction Migrants mental health is an issue of concern worldwide. We aimed to review studies on prevalence rates of depression and/or anxiety among refugees and labour migrants; to evaluate associations between the Gross National Product (GNP) of the immigration country and depression and anxiety.

Methods Systematic literature for population based studies reporting prevalence rates of depression and/or anxiety according to DSM- or ICD- criteria; and calculation of combined estimates with the Dersimonian-Laird estimator for proportions with the respective $\mathrm{CI}$.

Results 348 records; with 37 on 35 populations meeting the inclusion criteria. 35 studies were included in the final analysis. Combined prevalence rates for depression among labour migrants were $20 \%$ ( $95 \%$ CI $14 \%$ to $26 \%$ ) vs $44 \%$ (95\% CI $27 \%$ to $62 \%$ ) among refugees; for anxiety among labour migrants $21 \%$ (95\% CI $14 \%$ to $29 \%$ ) vs $40 \%$ among ( $95 \%$ CI $23 \%$ to $49 \%$ ) ( $n=24051$ ). Higher GNP in the country of immigration was related to lower symptom prevalence of depression and/or anxiety in labour migrants; but not in refugees.

Conclusion Depression and/or anxiety in labour migrants and refuges needs to be considered separately. The GNP of the host country appears to be related to better mental health in labour migrants but not in refugees.

\section{P2-440 ORGANISATIONAL AND HEALTH FACTORS AMONG WORKERS AND THEIR SUPERVISORS IN EXPORT PROCESSING ZONES IN THE PHILIPPINES}

doi:10.1136/jech.2011.142976l.70

$\mathrm{J} \mathrm{L}$ Lu. ${ }^{*}$ National Institutes of Health, University of the Philippines Manila, Manila, The Philippines

Introduction We investigated the relationship between organisational/management factors at work with health factors in the manufacturing sector.

Materials and Methods A survey was undertaken in 23 establishments, including 630 workers, and 47 supervisors. In addition, 10 focus group discussions (FGDs) for workers, and 5 FGDs for supervisors were undertaken.
Results Workers and supervisors both reported illnesses and job dissatisfaction. The survey found that the most prevalent issues among workers were: the need to upgrade skills (76.3\%), feeling pressured in doing work (60.5\%), fast paced work (60.5\%), repetitive work $(63 \%)$, and that work is both physically and mentally tiring (59.7\%). Among supervisors the issues raised included: work described as challenging and stimulating (66\%), needing regular upgrading of skills (46.8\%), and needing literature on information technology (31.9\%). Focus group discussions showed that workers and supervisors were confronted with stress, fast-paced work, the need to upgrade skills in order to accommodate new information technology into the work production, fatigue, re-engineering and downsizing by management, low job control and difficult worker-supervisor relationship.

Conclusions This study was able to show that health of workers and supervisors is affected by both organisational and management factors at work.

\section{P2-441 OCCUPATIONAL HAZARDS AND ILLNESSES OF FILIPINO WOMEN WORKERS IN EXPORT PROCESSING ZONES}

doi:10.1136/jech.2011.142976l.71

S F Lu, J L Lu.* National Institutes of Health, University of the Philippines Manila, Manila, The Philippines

This was a baseline study on the occupational exposures and health problems among women workers in Export Processing Zone with employers from foreign multinationals such as Americans, Europeans Japanese, Chinese, and Indians. Physical, chemical and ergonomic hazards were evaluated and measured through workplace ambient monitoring, survey questionnaires, and interviews among 24 industries, and 500 respondents (majority were female at $88.8 \%$ ). The top 5 hazards were ergonomic hazards $(72.2 \%)$, heat $(66.6 \%)$, overwork (66.6\%), poor ventilation $(54.8 \%)$ and chemical exposure (50.8\%). The most common illnesses were gastro-intestinal problems (57.4\%), backache (56\%), headache (53.2\%) and fatigue/ weakness $(53.2 \%)$. Logistic regression shows association between certain work-related factors and occupational illnesses, and psychosocial problems. Highly significant associations were hearing loss with years spent in the company $(p=0.005)$ and gender $(p=0.006)$; headache and dizziness with poor ventilation $(p=0.000)$; backache with prolonged work $(p=0.003)$. These results will have implications for policy and program formulation for women worker's concerns and issues in the export zones.

\section{P2-442 EUROPEAN ANCESTRY, PHENOTYPIC CHARACTERISTICS AND RISK OF CUTANEOUS MELANOMA: A CASE-CONTROL STUDY IN SAO PAULO, BRAZIL}

doi:10.1136/jech.2011.142976l.72

${ }^{1,2} \mathrm{O}$ Luiz, ${ }^{* 1,3} \mathrm{R}$ Gianini, ${ }^{1} \mathrm{G}$ Francisco, ${ }^{1} \mathrm{~F}$ Toledo, ${ }^{1} \mathrm{~S}$ Souza, ${ }^{1} \mathrm{~J}$ Sanches, ${ }^{1} \mathrm{C}$ Festa-Neto ${ }^{1} \mathrm{G}$ Gattas, ${ }^{1} \mathrm{R}$ Chammas, ${ }^{1} \mathrm{~J}$ Eluf-Neto. ${ }^{1}$ Faculdade de Medicina da Universidade de São Paulo, Sao Paulo, Sao Paulo, Brazil; 'Faculdade de Medicina do ABC, Santo Andre, Sao Paulo, Brazil; ${ }^{3}$ Pontificia Universidade Católica de São Paulo, Sorocaba, Sao Paulo, Brazil

Cutaneous melanoma shows high rates of mortality and its incidence has increased worldwide over the last century. This also is the trend for Brazil. Identified risk factors for melanoma include the pattern of sun exposure, family history of melanoma, number of nevi and phenotypic characteristics. Ethnicity could also influence the outcome of melanomas like European ancestry in different populations. We carried out a hospital-based case-control study in Brazil to evaluate the contribution of phenotypic factors and European ancestry to melanoma risk. A total of 412 subjects (202 